\title{
PRIORITIZATION OF RESEARCH UNDER NATIONAL AIDS CONTROL PROGRAMME IN INDIA USING NOMINAL GROUP TECHNIQUE
}

\author{
Sogarwal R, Bachani D \\ Ministry of Health \& Family Welfare, Government of India, New Delhi
}

\begin{abstract}
Introduction: During the first 2 years of the five year plan of India's National AIDS Control Programme Phase-III (NACP-III; 2007-12), various interactive consultative workshops were organized in collaboration with development partners with the objective of identifying priority areas for operational research and further development of research protocols adopting mentorship approach.

Methodology: This article is an attempt to present the Nominal Group Technique (NGT) which was used to identify a set of fundable and practically feasible research priorities under NACP-III specifically focusing on Prevention of Parent to Child Transmission (PPTCT) and Pediatric HIV Care in India. The activity was undertaken with support of UNICEF in the year 2010. A total of 110 persons participated in the consultation clustering into 37, 36 and 37 members in Group A, B and C, respectively. The participants reflected the mix of policy makers / decision makers (8), programme managers (12), implementers (36), subject experts / researchers (28), other stakeholders (16).

Results: A total of nine highest priority research questions were identified by all the groups in the assigned themes. The value of Kendall's $W$ coefficient of concordance was 0.68 , which shows significant agreement among raters on priority research questions (chi-square $=16.35 ; p=0.03$ ).

Conclusion: Based on our experience, we can conclude that NGT was found to be an important tool for setting research priorities that is more democratic and transparent than the traditional methods. By applying various stages of the group sessions, participants can experience the rethinking process with reference information to enhance their judgment. The results of our experience may help programme managers / policy makers to plan similar and more improved method in other element of NACP as well as other health programmes.
\end{abstract}

Key words: Research, HIVIAIDS, Nominal group technique, India

\section{INTRODUCTION}

During the India's National AIDS Control Programme ${ }^{1}$ phase I (1992-1999) and phase II (1999-2006), a number of regional and national level studies, assessments, surveys, operational, biomedical and laboratory research were conducted. ${ }^{2,3}$ These studies and surveys have

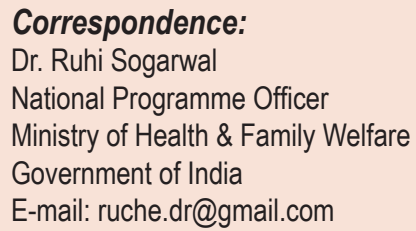

contributed to better understand the dynamics of the HIV epidemic ${ }^{4}$. However, issues of quality research and knowledge translation continued to be of concern specifically due to inadequate documentation and dissemination practice. The lessons learnt from the experience of NACP- I and NACP-II, led to an agreement on the goal, objectives and strategies for National AIDS Control Programme Phase III (NACP-III; 2007-12). ${ }^{2}$ Under NACP-III, several new initiatives have been taken to scale-up HIV research with emphasis on multidisciplinary themes, improved research quality, expanded partnerships, utilization of research based knowledge, relevant context specific indicators for tracking the epidemic. Some of the 
initiatives were system development; research prioritization, dissemination strategies, constitution of Network of Indian Institutions for HIVIAIDS Research, fellowship scheme and capacity building initiatives. Government of India recognized that the magnitude of the response to HIV epidemic in India cannot be managed centrally and therefore under NACP- III, programme implementation was decentralized to District and Sub District levels. Thus there is now concern for priority setting process to get more representative evidences for decision makers, which is an important and essential approach for understanding the problem and optimal resource allocation.

In India, lack of emphasis has been observed on research, specifically Operational Research (OR), because there is uncertainty on how to conduct it; what kinds of evidence can and should be used to determine whether HIV prevention programs and interventions really work? How do we best drive evidence? etc. ${ }^{4}$ Literature suggest ${ }^{3,4,5}$ that research should not necessarily be viewed separate from programming, it should be included in programme design, planning, monitoring and evaluation. If it is included in an early stage, it becomes clear why it will be needed, what the scope of the research will be and what would be the logistical requirements? Having selected high level strategies to prioritize and target resources, research will help in selection of the appropriate types and mixes of specific interventions and service modalities. ${ }^{6,7}$ It is well recognized that the collaboration of researchers and decision makers from prioritizing and planning of research to dissemination can strongly affect an impact of a single study. ${ }^{8-10}$ During the first 2 years of the five year plan of NACP-III, various interactive consultative workshops were organized in collaboration with development partners (e.g. UNICEF / UNAIDS / CDC) with the objective of identifying priority areas for operational research under NACP-III and further development of research protocols adopting mentorship approach.

This article is an attempt to present the Nominal Group Technique (NGT) ${ }^{11}$ which was used to identify a set of fundable and practically feasible research priorities focusing on Prevention of Parent to Child
Transmission (PPTCT) and Pediatric HIV Care of India's NACP-III. The process was undertaken with support from UNICEF in the year 2010.

\section{METHODOLOGY}

\section{Categorization of topics}

Beyond the general classification ${ }^{11}$, research in the HIVIAIDS domain under NACP-III was divided into two main categories: 1) prevention of HIV transmission and, 2) mitigation of the effects of HIVIAIDS, as summarized in Table-1. The first category focuses on the full range of policies and programs directed in preventing HIV transmission, whereas the second category focuses on a range of program activities directed in reducing the impact of HIVIAIDS including treatment, care and support. In these two categories, we sought potential research topics from all the programme divisions during the first year of the NACP-III. We requested programme head of every division to suggest programme / knowledge gaps concerned to their programme. They were encouraged discussion among their division with their junior staff as well as implementation partners to identify atleast programme gaps. The programme / knowledge gaps were collected anonymous and so reminders to non-respondents could not be sent. However, we sent reminders to the divisional heads to provide the information as per the stipulated time period.

\begin{tabular}{|c|c|}
\hline $\begin{array}{l}\text { Program } \\
\text { Area }\end{array}$ & Key Program Elements \\
\hline $\begin{array}{l}\text { HIV } \\
\text { Prevention }\end{array}$ & $\begin{array}{ll}\text { - } & \text { Targeted interventions for } \\
& \text { High Risk Groups and Bridge } \\
& \text { Populations } \\
\text { - } & \text { Management of STI/RTI } \\
\text { - } & \text { Condom programming } \\
\text { - } & \text { Blood Safety } \\
\text { - } & \text { Integrated Counseling and } \\
& \text { Testing Centres } \\
\text { - } & \text { Post-exposure Prophylaxis } \\
\text { - } & \text { Prevention of Parent-to-Child } \\
& \text { Transmission } \\
\text { - Information Education and } \\
\text { Communication }\end{array}$ \\
\hline
\end{tabular}


Table 1. Continuous

\begin{tabular}{|l|ll|}
\hline HIVIAIDS & $\bullet$ & Anti-retroviral Therapy \\
Mitigation & $\bullet$ & Management of Opportunistic \\
& Infections (OIs) \\
& $\bullet \begin{array}{l}\text { Community care and Home- } \\
\text { based support } \\
\end{array}$ & $\begin{array}{l}\text { Advocacy and stigma } \\
\text { reduction }\end{array}$ \\
\hline
\end{tabular}

The collected information from all programme heads was complied broadly in above mentioned two main categories. Incomplete sentences and duplicate areas / gaps were excluded from the frame. Finally, 48 most frequently suggested programme / knowledge gaps were selected and are listed in Box-1. Based on the consensus of the donors, programme mangers / policy makers, following three themes on PPTCT and Pediatric HIV care were identified from the list (Box-1) for research prioritization through NGT:

(1) PPTCT program effectiveness and coverage

(2) Pediatrics HIV Care and Treatment (3) Convergence of PPTCT and Pediatrics HIV Care with the National Rural Health Mission (NRHM) ${ }^{13}$ / Reproductive and Child Health (RCH). ${ }^{14}$

\section{Composition of Nominal Group}

The NGT is a structured form of brainstorming in which several people are organized to work as a team to resolve a problem. Within the group work, sharing of ideas promotes a sense of involvement and motivation. ${ }^{15}$

The composition of the nominal group was intended to reflect the diversity in the consultation process. The criteria for selection required that the participant should have (1) at least three years of experience as programme managers / decision makers in PPTCT and Paediatric HIV care programme, (2) recognition as an expert in the relevant field, (3) involvement in the implementation of the concerned element of the programme. The selection criteria were defined to ensure that the questions addressed during the consultation were properly considered and resolved. Hence, the participants were selected from a population of policy makers / decision makers, programme managers, implementers, subject experts I researchers and other stakeholders.

\section{Nominal Group Process}

Based on the pre-determined themes, the participants were arranged into following 3 groups for interactive deliberations: Group A on PPTCT Program Effectiveness and Coverage; Group B on Pediatrics HIV Care and Treatment; and Group C on convergence of PPTCT and Pediatrics HIV Care with the NRHM/RCH and health system issues. Each group consisted of (1) a group leader, who was responsible for ensuring that the discussion remains focused on achieving consensus on the priority research questions; (2) a rapporteur who was responsible for documenting the technical summary of the group work discussion and conclusions; (3) members, who contributed in the discussion based on their knowledge and experience. The purpose of the group work was to discuss the program gaps and frame questions that group considered to be the most crucial for addressing the gaps in the assigned theme.

To make the best use of the allotted time to accomplish the output goals, it was important that the group stayed focused on identifying the key research questions needed to address the gaps in knowledge / programme rather than spending a lot of time discussing the programmatic challenges. Hence, the group sessions were divided into four stages. During the first stage, groups were asked to brainstorm on the assigned theme addressing three key questions; (1) what are the five highest priority OR for addressing key gaps in the group's assigned area?; (2) for each of the five questions chosen, a brief rationale for why the group selected these as the most crucial OR priorities; (3) for each of the five questions chosen, outlined the potential research design and data sources.

At second stage, each member within the group was asked to indicate their level of support to each of the identified research questions / areas individually using likert scale of 1 to 9 (1=no support, $5=$ moderate support, $9=$ strong support) so as to get the group's ranking, an attempt to reach 
a group consensus. The members were under no pressure to achieve consensus.

At third stage, each group leader had presented brief overview of the exercise and displayed their priority research questions to other group members using the power-point template for about 20 minutes. Each group had also given the rationale of identifying the particular research questions as priority. Thus, a total of 25 priority research questions were identified by all the groups in the assigned theme. Participants were allowed to express their disagreements with adequate reasons at the end of the presentation. Assuming that full consensus was not achieved, voting was used to obtain majority views considering six parameters: (1) Can the questions be answered through well designed and conducted OR? (2) Would the OR study needed to answer the question be feasible within the current ethical, population and financial environment (logically, financially, timely)? (3) Will answering the research question add significantly to the PPTCT and Pediatrics HIV care knowledge base? (4) Will answers to the research questions be relevant, useful and generalizable to the national efforts to scale up PPTCT and Pediatrics HIV care? (5) Will answering the OR question have a large impact on the epidemic and/or the survival of the HIV infected population? (6) Will it be feasible to rapidly and widely implement the results of the $O R$ study needed to address the research questions (Logistically, financially, and timely)? Voting was done using the four-point scale ( $1=$ not likely to fulfill the criteria; $2=$ may possibly fulfill the criteria; $3=$ likely to full fill the criteria; $4=$ certainly fulfill the criteria) through self elimination method. The technique was carried out in a group session that lasted on an average 90 minutes. The voting was made anonymous to maintain confidentiality with no pressure.
At final stage, the scores given by all the participants were analyzed and presented to categorize the highest priority research questions that emerged through NGT in the consultation.

\section{Data Analysis}

For each identified research questions, the individual ranks from participants were collated and the scores were indicated by the mean values. The research question scoring the lowest mean value was considered as the least priority areas, while the one scoring the largest mean value was taken as the most priority areas. Kendall's W coefficient of concordance ${ }^{16}$ was applied, which is a measure of agreement among raters. Kendall's $W$ ranges are between zero (no agreement) and one (complete agreement). Statistical analysis was performed using SPSS 16.0

\section{RESULTS}

Of the 115 people invited, 6 declined to participate ( 3 of which were replaced) and 2 refused to attend on very first day of the consultation. Finally, a total of 110 people participated in the consultation clustering into 37, 36 and 37 members in Group $A, B$ and $C$, respectively. The participants reflected the mix of policy makers / decision makers (8), programme managers (12), implementers (36), subject experts / researchers (28), other stakeholders (16).

At the first stage of the group sessions, participants of each group had initially discussed knowledge I programme gaps, priority research questions addressing these gaps on assigned theme. Some of the examples of the outcome of the discussion from each group are given in the Table 2 . 
Table 2. Examples of Programme / Knowledge gaps and Priority Research Questions on PPTCT and Pediatric HIV care and treatment in India.

Programme / Knowledge gap Priority Research Questions

\section{Group-A: PPTCT Program Effectiveness and Coverage}

\begin{tabular}{ll}
$\begin{array}{l}\text { All ANC cases are not counseled and } \\
\text { tested for HIV. }\end{array}$ & $\begin{array}{l}\text { What are facilitating and inhibiting factors in counseling } \\
\text { and testing for HIV during ANC? }\end{array}$ \\
\hline $\begin{array}{l}\text { Increase in Institutional delivery does } \\
\text { not commensurate with PPTCT scale- }\end{array}$ & $\begin{array}{l}\text { What are the determinants of not providing anti-retroviral } \\
\text { prophylaxis to HIV positive mothers opting for Institutional } \\
\text { delivery? }\end{array}$
\end{tabular}

Group-B: Pediatrics HIV Care and Treatment

Access to Pediatric ART services are

How to make Pediatric HIV services accessible \& child inadequate friendly to all Children living with HIV (CLHIV)?

Poor follow-up of HIV exposed child (HEC)

What are the reasons and possible actions required for follow-up of HEC?

\section{Group-C: Convergence of PPTCT and Pediatrics HIV Care with the NRHM/RCH and health system issues}

Huge gap between HIV diagnosis and ART prophylaxis.
Will utilization of service providers of NRHM / RCH improve the uptake of PPTCT?

How to increase access to ART Prophylaxis and

Treatment by HIV+ pregnant women?

Have the existing Public Private Partnership models (Yeshswini and Chiranjeevi) been effective in coverage and quality of the PPTCT services

During the second stage, identified research questions were ranked within the group to reach out to the consensus. A total of 25 priority research questions were identified during the consultation based on the mean rank. These 25 questions were further summarized into broad 5 areas: (1) access to PPTCT, (2) strategy to increase PPTCT uptake, (3) follow up and care of HIV exposed children, (4) nutritional care of HIV exposed children or CLHIV and Private sector participation. Some of the examples are given in Table 3. Key priority areas/research questions suggested by programme officials under NACP-III are given in box 1 . 
Table 3. Examples of Priority Research Areas identified through $2^{\text {nd }}$ Stage of NGT

Research Areas Priority Research Questions

Access to PPTCT 1 . What are the various factors that impact on HIV positive mothers accessing the range of PPTCT services,

2. What are facilitating and inhibiting factors in counselling and testing for HIV during ANC?

3. How to increase access to ART Prophylaxis \& Treatment by HIV+ pregnant women?

Strategy to increase

PPTCT uptake

4. Is single window service delivery system feasible for HIV positive mothers and their exposed children?

5. What are the communication needs in the context of clinical settings where PMTCT services are delivered/accessed?

6. Will utilization of service providers of NRHM / RCH improve the uptake of PPTCT?

Follow-up and care of HIV

7. How to improve Follow up of HIV exposed children?

Exposed Children (HEC)

8. How to make Infant feeding practices safe for HEC?

9. How can convergence between Paediatric health services (e.g. immunization) help in tracking and follow up of exposed children?

10. Can HIV-IMNCl increase the coverage of tracking of exposed child, and Paediatric HIV care?

11. What are the barriers/issues for the exposed child, in accessing the services?

Nutrition of CLHIV/HEC

12. How to improve Nutritional status among CLHIV?

13. How to make Infant feeding practices safe for HEC?

Private sector participation

14. Have the existing PPP models (Yeshswini and Chiranjeevi) been effective in coverage and quality of the PPTCT services?

At the final stage of the consultation, 9 out of these 25 research priority areas topped based on the mean rank. The mean rank given by three groups to the 9 highest priority research questions is shown in Table 4. The value of Kendall's $W$ coefficient of concordance was 0.68 , which shows significant agreement among raters on priority research questions (chi-square $=16.35 ; p=0.03$ ). 
Table 4. Group-wise Mean Rank of Priority Research Questions using Kendall's W test

\begin{tabular}{|c|c|c|c|c|c|c|}
\hline \multirow[t]{2}{*}{ Priority Research Question } & \multicolumn{2}{|c|}{ Group A (N=39) } & \multicolumn{2}{|c|}{ Group B (N=36) } & \multicolumn{2}{|c|}{ Group C (N=37) } \\
\hline & $\begin{array}{l}\text { Mean } \\
\text { Rank }\end{array}$ & Rank & $\begin{array}{l}\text { Mean } \\
\text { Rank }\end{array}$ & Rank & $\begin{array}{l}\text { Mean } \\
\text { Rank }\end{array}$ & Rank \\
\hline $\begin{array}{l}\text { What are the various factors that } \\
\text { impact on HIV positive mothers } \\
\text { accessing the range of PPTCT } \\
\text { services? }\end{array}$ & 3.19 & 8 & 3.26 & 8 & 3.34 & 8 \\
\hline $\begin{array}{l}\text { What are facilitating and inhibiting } \\
\text { factors in counseling and testing for } \\
\text { HIV during ANC? }\end{array}$ & 2.54 & 6 & 2.78 & 6 & 3.28 & 7 \\
\hline $\begin{array}{l}\text { How to make Infant feeding practices } \\
\text { safe for HIV exposed children? }\end{array}$ & 2.42 & 5 & 2.66 & 3 & 3.00 & 2 \\
\hline $\begin{array}{l}\text { Is single window service delivery } \\
\text { system feasible for HIV positive } \\
\text { mothers and their exposed children? }\end{array}$ & 2.58 & 7 & 2.63 & 2 & 3.18 & 4 \\
\hline $\begin{array}{l}\text { How to improve Follow up of HIV } \\
\text { exposed children? }\end{array}$ & 2.33 & 4 & 2.67 & 4 & 3.22 & 6 \\
\hline $\begin{array}{l}\text { Will utilization of service providers of } \\
\text { NRHM / RCH improve the uptake of } \\
\text { PPTCT? }\end{array}$ & 2.03 & 2 & 2.74 & 5 & 3.21 & 5 \\
\hline $\begin{array}{l}\text { How to improve Nutritional status } \\
\text { among CLHIV? }\end{array}$ & 1.77 & 0 & 2.94 & 7 & 3.10 & 3 \\
\hline $\begin{array}{l}\text { How can convergence between } \\
\text { Paediatric health services (e.g. } \\
\text { immunization) help in tracking and } \\
\text { follow up of exposed children? }\end{array}$ & 2.07 & 3 & 2.44 & 0 & 2.10 & 0 \\
\hline $\begin{array}{l}\text { What are the communication needs } \\
\text { in the context of clinical settings } \\
\text { where PMTCT services are delivered/ } \\
\text { accessed? }\end{array}$ & 1.99 & 1 & 2.55 & 1 & 2.50 & 1 \\
\hline Kendall's W test & 0.68 & & & & & \\
\hline Chi-square & 16.35 & & & & & \\
\hline Asymp. Sig. & 0.03 & & & & & \\
\hline
\end{tabular}




\section{Box 1. Key Priority Areas / Research Questions Suggested by Programme Officials under NACP-III}

1. Health care seeking behaviour and treatment literacy in High Risk Groups (HRG).

2. Determinants of high risk behaviours of different vulnerable groups and hard to reach population.

3. Impact Assessment of Targeted Intervention Programme.

4. Cost-effective and cost-benefit analysis of Interventions.

5. Understanding sexual networks of migrants and vulnerabilities at the source as well as destination sites.

6. Profile and quality of counselors of ICTC.

7. Factors affecting acceptance of HIV testing by various groups including ANC cases.

8. Estimation of CD4 count of newly detected HIV positive person in the ICTC.

9. Assessment of CD4 status of newly detected HIV positive mothers in the PPTCT centers.

10. Evaluation of impact of PPTCT intervention in terms of HIV transmission to new born.

11. Barriers and uptake of Integrated Counseling and Testing Center (ICTC) services by HRGs/pregnant women

12. Strategy to increase PPTCT uptake.

13. A community based study for understanding the load of Sexual / Reproductive Transmitted Infections (STI/RTI).

14. Impact of PPP scheme in reducing the STI load in the community.

15. Cost-effectiveness and monitoring types of providers.

16. Efficacy of syndromic management of common STIs.

17. Factors affecting treatment seeking behaviour for STIs.

18. Drug resistance towards common STIs.

19. Community based rapid assessment of STIs in general population/HRGs.

20. Socio-demographic and clinical profile of HIV-TB co-infected person.

21. Study on Knowledge Attitude and Practices of New Prevention Technologies.

22. Role of community based outreach workers.

23. In-depth study on condom usage in different situations (regular versus casual partners).

24. Psychosocial and Mental morbidity among People Living With HIVIAIDS (PLHA).

25. Communication Needs Assessment for PLHAs and HRGs.

26. Reach and Effectiveness of Information Education and Communication (IEC).

27. Content analysis of the IEC material.

28. Impact evaluation of needle-syringe program.

29. Adherence to ART in injecting drug users.

30. Determinants of HIV infection among new and old Injecting Drug Users in North Eastern states of India

31. Determinants of initiation of drug use of women and effect of drug use on women and families.

32. Dynamics of HIV transmission in injecting drug users.

33. Changes in profile of drug users and drug use behavior.

34. Transitioning from non-injecting to injecting drug use.

35. Efficacy of thrice weekly ATT for HIV-TB patients.

36. Determinants of ARV Drug Adherence in India.

37. Factors affecting enrollment of PLHAs on ART.

38. Quality of services given by counselors of ART.

39. Efficacy and drug resistance of single dose NVP in PMTCT.

40. Process Evaluation of Link ART centres and Community Care Centers.

41. Reference ranges for CD4 T-cell counts in adult Indian population.

42. Impact Assessment of Home based care and support services.

43. ART survival and Quality of life.

44. Reasons for default among pre ART and ART patients

45. Review of organizational capacity of NACO and State AIDS Control Society (SACS).

46. Models for integration of HIVIAIDS related activities with National Rural Health Mission and how effective the integration would be.

47. Decentralized Management in scaling-up and Sustaining HIVIAIDS prevention, care, and treatment services

48. Population based study on HIV prevalence 


\section{DISCUSSION}

The probability ofsuccessofaresearch planisgreatly enhanced when the "beginning" is correctly defined as a precise statement of goals and justification. Having accomplished this, the sequential steps necessary for developing a research plan makes research execution easier to organize $e^{17,18}$. The consultative process makes research hugely valuable to the programme planners and policy makers. It can help in understanding problems/ gaps more clearly to develop better strategies for dealing with them ${ }^{19}$. Considering the above, NACO in alliance with development partners organized a series of consultative workshops from prioritization of research to knowledge translation so as to generate evidences for programme development and policy formulation.

Research based on the programme gaps and ending in action will most likely assure a successful planning and policy making. Since this article sought to explore the application of the sequential stages of NGT in identifying problems and setting research priorities, this technique appears to be a useful methodological approach as found elsewhere. . $0,21,22^{2}$ This technique was found to be an important tool for setting research priorities that is more democratic and non-hierarchical than the traditional methods. It allows free exchange of opinions and generation of ideas. Face to face dialogues between the multi-skilled team of researchers / subject experts, implementers, programme managers and policy makers was enormously productive. Participants had adequate opportunities during various stages of NGT and active participation during the final discussion session before voting. It could be possible that individual opinions prior to voting might have changed and leading to higher level of agreement. On the other hand, studies that have the widespread support of the funders are more likely to gain cooperation and participation in their execution and may increase the likelihood of any research findings being taken up for policy change.

As noted earlier, the NGT consisted of four steps namely: simple ranking, discussion, voting and comparison of results / agreements of raters.
Although the ranking provides a rough indication of the priority areas, it may not provide the rationale of prioritizing the area. However, during the first stage of group session, we tried to capture the rationale of identification of the programme / knowledge gaps in the priority frame. During the planning stage of NGT, we also made the provision to outline the research design on the identified priority research questions. However, due to limited time period and inadequate representation of experts from statistics/biostatistics and demography disciplines, the groups could not attempt research design. Despite the fact that many stages are involved, this technique uses less time than other types of methods. ${ }^{23}$

To take up the outcome of the process forward, the group recommended the constitution of working groups for each of the respective highest priority research questions to develop detailed proposals. It was found that among the highest priority research questions; there are two different kinds of studies: (1) short term studies, which can influence the implementation of the current phase of NACP strategies, (2) longer term studies, which can influence the formulation of next phase of NACP. Long term plans are usually for 5 year period and coincide with 5-year development plans. India's $11^{\text {th }}$ Five-Year Development Plan is ending in March 2012 and $12^{\text {th }}$ Plan will begin in April 2012 and end in March 2017. Research studies planned in advance help in producing evidence that goes into 5 year planning cycle.

\section{CONCLUSION}

Based on our experience, we can conclude that NGT was found to be an important tool for setting research priorities that is more democratic and transparent than the traditional methods. By applying various stages of the group sessions, participants can experience the rethinking process with reference information to enhance their judgment. The results of our experience may help programme managers / policy makers to plan similar and more improved method in other element of NACP for e.g. Targeted Interventions for High Risk Groups as well as other health programmes. 


\section{ACKNOWLEDGMENTS}

Authors gratefully acknowledge Dr. Ranjit Roy Chuadhury, Chairperson of Technical Resource Group on Research and Development and expert members of the group who has given direction to the National AIDS Control Programme to develop appropriate research agenda. We also acknowledge Dr. Charles Gilks, Country Coordinator-India, UNAIDS and Dr. Ivonne Cammaroni, Chief-HIV/AIDS-India, UNICEF for their valuable contribution. Finally, we acknowledge contribution of all the participants during the consultations who spared time and shared valuable thoughts to help us in prioritizing research areas under the Phase III of the National AIDS Control Programme.

\section{REFERENCES}

1. http://www.nacoonline.org/About_NACO. (Cited 2011 April 10).

2. National Project Implementation Plan for National AIDS Control Programme, Phase-III (2007-12), Government of India, New Delhi.

3. http://www.articlesbase.com/self-help-articles/ the-importance-of-research-why-we-doresearch-793360.html\#ixzz0yM4tl8wS. (Cited 2011 April 10).

4. Klein R. Research, policy and the National Health Service. J Health Politics, Policy Law, 1990;3:501523.

5. Strnad L. Importance of operational research methods for the improvement of a planning system for public health. Cas Lek Cesk. 1969;49:1463-5.

6. Manly BF. The Design and analysis of research studies. Cambridge University Press. Cambridge, England 1992:353.

7. Berresford A, Dando MR. Operational research for strategic decision making: The role of world-view. J Operational Res Soc 1978;2:137-146.

8. Huberman M. Linkages between researchers and practitioners: a qualitative study. Am Educational Res J 1990;2:363-391.

9. Selby SC, Drummond M, Hailey D. Increasing the impact of health technology assessments $\ln \mathrm{M} \mathrm{K}$ Chytil, G Durn, W van Eimeren and C D Flagle (eds) Health systems - the challenge of change. Prague: Omnipress 1992.
10. Buxton M, Hanney S. Assessing payback from Department of Health Research and Development: second report (two volumes). Uxbridge: Health Economics Research Group, Brunel University 1994.

11. Allen,J, Dyas J, Jones M. Building Consensus in Health Care: A Guide to using the nominal group technique. British J Comm Nursing 2004:9:110-4.

12. Weiss $\mathrm{CH}$. Organisations for policy analysis. New York. Sage Publications 1991.

13. National Rural Health Mission, Ministry of Health and Family Welfare, Government of India, 2005-12. http://mohfw.nic.in/NRHM/Documents/Mission_ Document.pdf. (Cited 2011 April 12).

14. Reproductive and Child Health Programme, Ministry of Health and Family Welfare, Government of India. http://www.mohfw.nic.in/NRHM/RCH/ Index.htm. (Cited 2011 April 12).

15. Delbecq, AL, Van de Van DH, Gustafson DH. Group techniques for program planning: A guide to nominal group and Delphi processed. Glenview III. Scott, Foresman.

16. Siegel S, Castellan Jr. NJ. Nonparametric statistics for the behavioral sciences (1988) International Edition.

McGraw-Hill Book Company. New York. ISBN 0-07057357-3:262-272.

17. Reis-Lehrer L. Grant application writers handbook. Jones and Barlett Boston. 1995:472.

18. Serrat $\mathrm{O}$. Linking research to practice. Knowledge Solution 2008; №. 7.

(http://www.adb.org/Documents/Information/ Knowledge-Solutions/Linking-Research-Practice. pdf).

19. Congdon JD, Dunham AE. Defining the beginning: the importance of research design research and management techniques for the conservation of sea turtles K. L. Eckert, K. A. Bjorndal, F. A. AbreuGrobois, M. Donnelly (Editors) IUCN/SSC Marine Turtle Specialist Group Publication 1999.

20. McMurray A. Three decision-making Aids: brainstorming, nominal group technique and Delphi technique. J Nursing Staff Dev 1994;10:62-5.

21. Maclachlan M. Identifying problems in community health promotion: an illustration of the Nominal Group Technique in AIDS education. Journal of Royal Society of Health, 1996;116:143-48. 
22. Carricks RS, Cockburn J Hirist S. Consulting about priorities for the NHMRC National Breast Cancer Center: how good is the nominal group technique. Australia-New Zealand J Public Health 1997;21:250-6.
23. Coreil, J. Group interview methods in community health research. Medical Anthropol 1995;16,193210. 